\title{
Refolded scFv Antibody Fragment against Myoglobin Shows Rapid Reaction Kinetics
}

\section{Hyung-Nam Song ${ }^{1,2}$, Jun-Hyuck Jang ${ }^{3}$, Young-Wan Kim ${ }^{3}$, Dong-Hyung Kim ${ }^{2}$, Sung-Goo Park ${ }^{1}$, Myung Kyu Lee ${ }^{1}$, Se-Hwan Paek ${ }^{2, *}$ and Eui-Jeon Woo ${ }^{1,4, *}$}

1 Medical Proteomics Research Center, Korea Research Institute of Bioscience \& Biotechnology, Daejeon 305-806, Korea; E-Mails: hotdog707@hanmail.net (H.-N.S.); sgpark@kribb.re.kr (S.-G.P.); mklee@kribb.re.kr (M.K.L.)

2 Department of Biotechnology and Bioinformatics, Korea University, Sejong 339-700, Korea; E-Mail:kdh5611@hanmail.net

3 Department of Food and Biotechnology, Korea University, Sejong 339-700, Korea; E-Mails: jangjunhyuck@naver.com (J.-H.J.); ywankim@korea.ac.kr (Y.-W.K.)

4 Department of Bio-analytical Science, University of Science and Technology, Daejeon 305-333, Korea

* Authors to whom correspondence should be addressed; E-Mails: ejwoo@kribb.re.kr (E.-J.W.); shpaek@korea.ac.kr (S.-H.P.); Tel.: +82-4-2879-8415 (E.-J.W.); +82-2-3290-3438 (S.-H.P.).

External Editor: Salvador Ventura

Received: 16 September 2014; in revised form: 1 December 2014 / Accepted: 12 December 2014 / Published: 18 December 2014

Abstract: Myoglobin is one of the early biomarkers for acute myocardial infarction.
Recently, we have screened an antibody with unique rapid reaction kinetics toward human
myoglobin antigen. Antibodies with rapid reaction kinetics are thought to be an early IgG form
produced during early stage of in vivo immunization. We produced a recombinant scFv
fragment for the premature antibody from Escherichia coli using refolding technology. The
$s c F v$ gene was constructed by connection of the $V_{\mathrm{H}}-V_{\mathrm{L}}$ sequence with a (Gly4Ser) 3 linker.
The scFv fragment without the pelB leader sequence was expressed at a high level, but the
solubility was extremely low. A high concentration of $8 \mathrm{M}$ urea was used for denaturation.
The dilution refolding process in the presence of arginine and the redox reagents GSH and
GSSH successfully produced a soluble scFv protein. The resultant refolded scFv protein
showed association and dissociation values of $9.32 \times 10^{-4} \mathrm{M}^{-1} \cdot \mathrm{s}^{-1}$ and $6.29 \times 10^{-3} \mathrm{~s}^{-1}$, 
respectively, with an affinity value exceeding $10^{7} \mathrm{M}^{-1}$ ( $\left.k_{\text {on }} / k_{\text {off }}\right)$, maintaining the original rapid reaction kinetics of the premature antibody. The refolded scFv could provide a platform for protein engineering for the clinical application for diagnosis of heart disease and the development of a continuous biosensor.

Keywords: single-chain variable fragment ( $\mathrm{scFv})$; premature antibody; myoglobin; acute myocardial infarction

\section{Introduction}

Recently, a premature antibody with rapid reaction kinetics was found, and its characteristics have been reported [1-5]. Antibodies with rapid reaction kinetics are thought to be produced during a premature stage of immunization in vivo. In the immune system, repetitive exposure to an antigen over an extended period of time gradually induces somatic hypermutation to produce ordinary antibodies that recognize their antigen with a slow dissociation rate and high binding affinity (e.g., 1000-fold), whereas the premature antibody is thought to be generated during an early stage of production. This is referred to as affinity maturation, which consists of the ongoing generation of B-cells receptor (BCR) due to somatic hypermutation and selection of these cells on the basis of affinity. IgM refers to those antibodies that are produced immediately after an exposure to the disease, while IgG refer to a later response. IgM is a temporary antibody that disappears within two or three weeks, which is then replaced by IgG [6]. Premature antibody is thought to belong to early generation of IgG type. Therefore, fewer exposures resulted in the production of antibody that reacts with its binding partner with rapid association and dissociation kinetics [1]. Research on the premature antibody is in an early stage, and the detailed binding mechanism of the rapid dissociation kinetics is currently not well understood.

There is a growing interest in antibodies with rapid reaction kinetics because of their potential application in recycling and continuous measurement systems [7-9]. Unlike conventional antibodies with a high affinity interaction, an antibody with rapid reaction kinetics can be used for a recycling system without the requirement of washing or a separate regeneration step. Continuous measurement can be achieved using a rapid reversible antibody immobilized on a label-free sensor to capture the analyte in the sample $[2,4,10]$. This concept could be used to construct a continuous sensor that can measure fluctuations in a low concentration of biomarkers in vivo. This type of continuous immunosensing technique can lead to a novel approach for monitoring and detecting early warning signs of the occurrence of a disorder, which can be applied using a direct online system in the future.

Myoglobin is one of the well-known and early diagnostic biomarkers of acute myocardial infarction (AMI) that can be detected within three hours after the onset of symptoms [11,12]. Myoglobin levels increase in the blood within $2 \mathrm{~h}$ after symptom onset of AMI, peak at six to nine hours, and return to normal within $24 \mathrm{~h}$. Numerous application studies have been published, and several recombinant antibody technologies have been reported on the usage of a myoglobin antibody, highlighting its importance as a biomarker and biomolecule for sensor development [13-15]. Because AMI is a typical disorder that requires continuous monitoring for early detection of potential life-threatening situations, protein engineering of a premature antibody against the myoglobin antigen could provide a suitable 
platform for development of a continuous biosensor system. Currently, there is no report on recombinant antibody engineering for the premature antibody and its application.

Recombinant antibody technologies for the handling of key antibody domains constitute an effective tool and have been increasingly used as alternatives to monoclonal Abs in medical diagnostic and therapeutic applications [16-18]. One of the most popular types of recombinant antibodies is the single-chain variable fragment ( $\mathrm{scFv}$ ) because it has been successfully modified into a number of different antibody formats and is easily expressed by several expression systems [19-21]. The scFvs contain the complete antigen-binding site, which includes the variable heavy $\left(V_{\mathrm{H}}\right)$ and variable light $\left(V_{\mathrm{L}}\right)$ domains of an antibody, which are able to bind selectively to a specific antigen. The $V_{\mathrm{H}}$ and $V_{\mathrm{L}}$ domains can be linked by one of various flexible linkers ( $\mathrm{scFv}$ ), by a disulfide bond ( $\mathrm{dsFv}$ ) or by both (sc-dsFv) [22,23]. However, the insoluble inclusion body formation of scFvs expressed in Escherichia coli is a significant problem [24,25]; therefore, a variety of methods for refolding proteins have been developed [26,27]. In this study, we expressed the insoluble scFv derived from the premature antibody against myoglobin in E. coli. We refolded the denatured protein in the presence of additives, such as arginine and a reducing agent, and the resultant $\mathrm{scFv}$ fragment retained its original features, such as rapid and reversible kinetics.

\section{Results}

\subsection{Construction and Expression of 2-7ds scFv for the E. coli System}

The $s c F v$ gene was constructed from the monoclonal antibody of two- to seven-days-old hybridoma cell clones immunized using myoglobin antigen (Figure 1A). The DNA plasmid with a hexa-histidine tag and a TEV cleavage site at the $N$-terminus was constructed in the expression vector of pET28a_pro with the (Gly4 $\left.\mathrm{Ser}_{1}\right)_{3}$ flexible linker between the heavy chain and the light chain of the variable regions. The pelB leader sequence, which directs the protein to the bacterial periplasm in ordinary bacterial expression of $\mathrm{scFv}$ for correct folding, was removed in this system because the initial expression and solubility was too low to detect (Figure 1B). The expression level of scFv was high on the SDS-PAGE gel compared with the protein with the pelB sequence. We found that the recombinant scFv fragment was mostly insoluble when located in the inclusion body (Figure 2A).

\subsection{Inclusion Body Isolation and Solubilization of the Recombinant Protein scFv}

In the inclusion body, many contaminant proteins were mixed with the target $\mathrm{scFv}$ protein. For purification of the inclusion body, the pellet was washed with DTT, which provides a reducing environment, and with Triton X-100 detergent, which solubilizes membrane debris. The inclusion body was successfully solubilized after it was denatured using $8 \mathrm{M}$ urea for $24 \mathrm{~h}$. We found that $13.8 \%$ of $\mathrm{scFv}$ in inclusion body was solubilized by $8 \mathrm{M}$ urea (Figure $2 \mathrm{~B}$ ). To obtain a high yield of scFv solubilization, it was essential to dissolve the inclusion bodies in an ample volume of the solubilization buffer $(1 \mathrm{~mL} / 20-40 \mathrm{mg})$ in the presence of $8 \mathrm{M}$ urea. Additional sonication processes were also effective for the complete removal of the pellet mass, whereas prolonged incubation resulted in higher solubilization. 
Figure 1. Construction of the premature $\mathrm{scFv}$ for protein expression in E. coli. The sequence of the premature $\mathrm{scFv}$ with a hexa-histidine tag and a TEV sequence in the $N$-terminus was shown with a (Gly4Ser) $)_{3}$ linker between the variable heavy $\left(V_{\mathrm{H}}\right)$ and variable light $\left(V_{\mathrm{L}}\right)$ regions. (A) The insert of the $s c F v$ genes was amplified using PCR; (B) The NheI (5') and XhoI (3') restriction enzymes were used for the subcloning; and (C) Schematic diagram of the vector plasmid for E. coli expression.
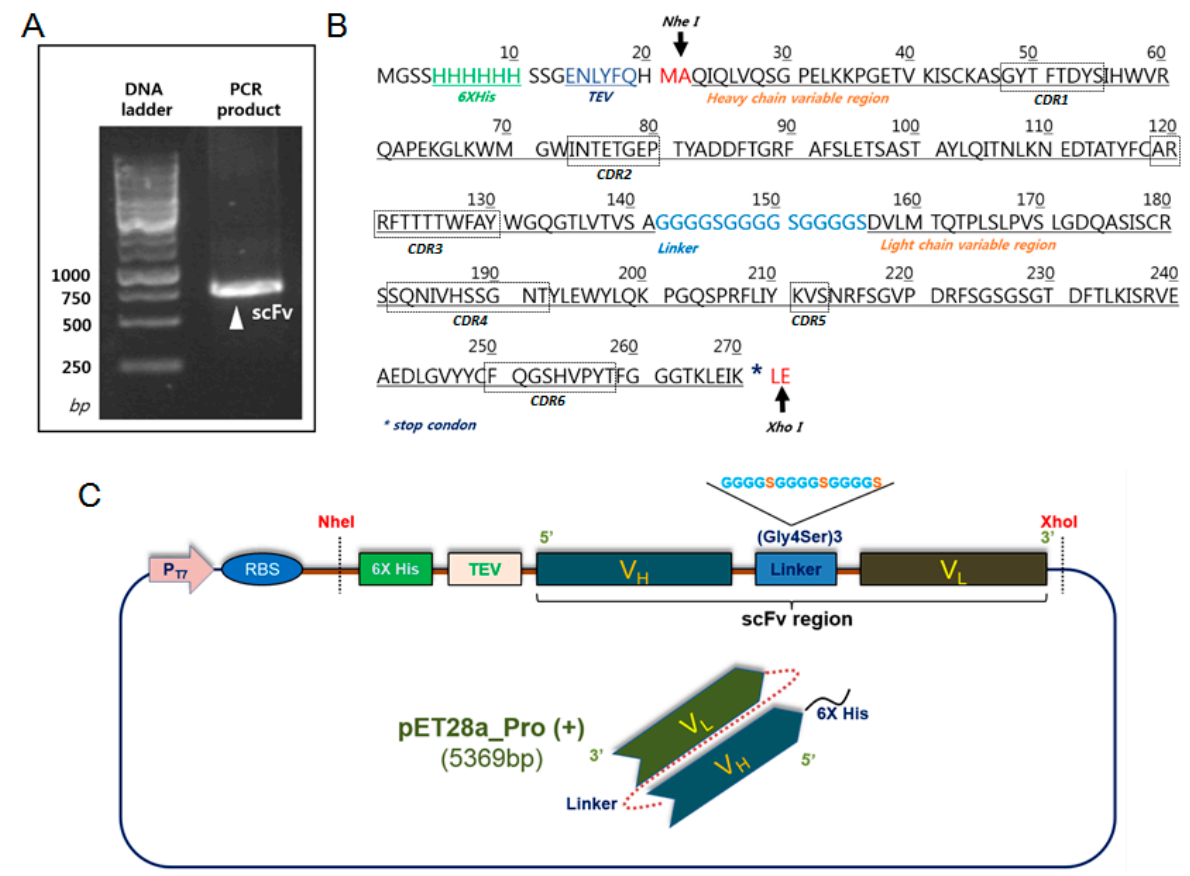

Figure 2. The expression, isolation and solubilization of the $\mathrm{scFv}$ protein from E. coli. (A) The recombinant scFv showed high expression after IPTG induction (AI), corresponding to $30 \mathrm{kDa}$ in SDS-PAGE (top) and Western blot analysis (bottom) compared with pre-induction (BI); (B) SDS-PAGE analysis of the inclusion bodies (IB). The pellet and the solubilized $\mathrm{scFv}$ using $8 \mathrm{M}$ urea were separated by centrifugation; and (C) Schematic diagram of the scFv refolding steps.
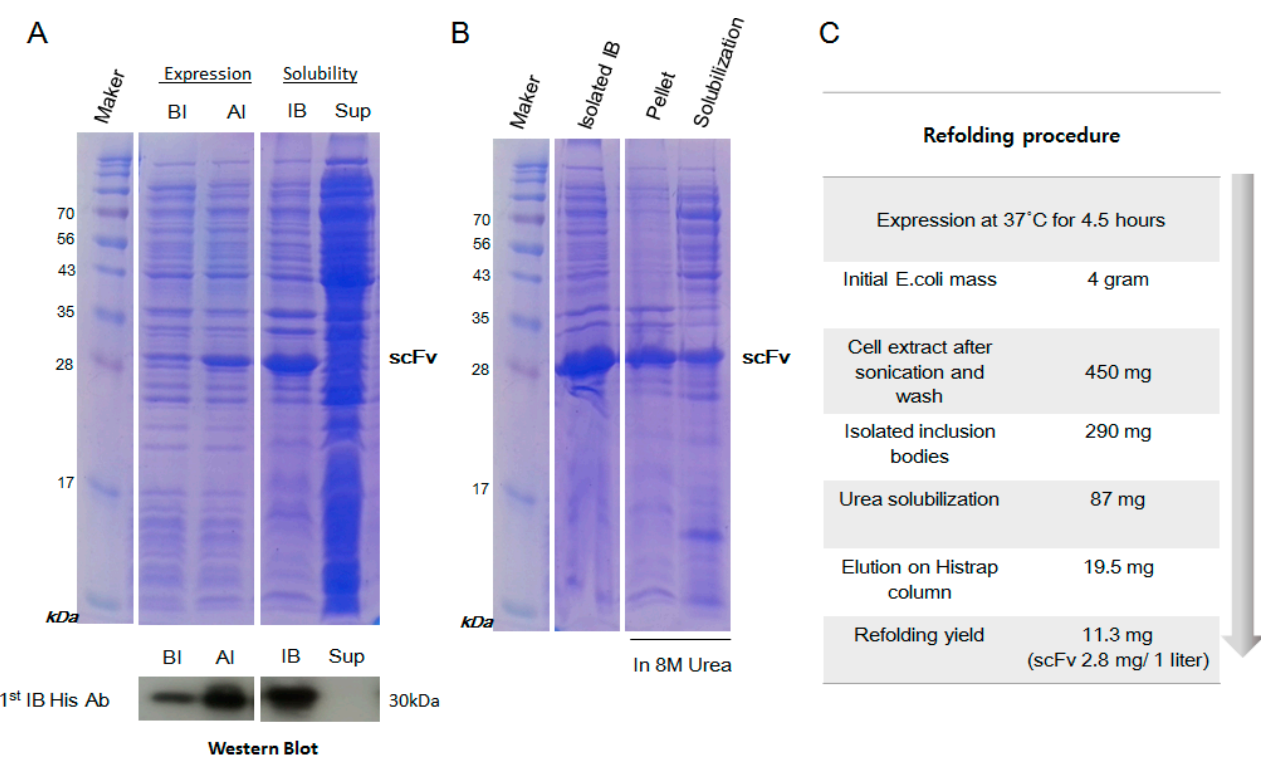


\subsection{Purification and Refolding of scFvs by Rapid Dilution}

The solubilized scFv was purified using a nickel chelate column, and the eluted scFv was directly subjected to a refolding step (Figure 3A). It was clearly observed that the concentration of the initial protein samples was an important factor for the refolding of scFv. A high protein concentration (greater than approximately $10 \mathrm{mg} / \mathrm{mL}$ ) caused significant aggregation upon denaturation of $\mathrm{scFv}$, whereas a low concentration of $\mathrm{scFv}$ (approximately $3 \mathrm{mg} / \mathrm{mL}$ ) showed a good refolding yield. Because the reducing environment inside the $E$. coli system is inappropriate for the folding of $\mathrm{scFv}$, redox reagents, such as reduced glutathione GSH and oxidized glutathione GSSH, were added for optimal folding of scFv in vitro. In the refolding step, the proper level of GSH and GSSH was an important factor, and the refolding buffer containing $2 \mathrm{mM}$ of GSH and $0.2 \mathrm{mM}$ of GSSH in a 10:1 ratio provided a good refolding yield in this study. To avoid any unnecessary reduction of the disulfide linkage in the cysteine residues, traces of any reducing agents, such as $\beta$-mercaptoethanol or DDT, were removed in subsequent buffers. L-arginine was the key element for minimal aggregation of the denatured protein and for an increase in the solubility of the scFv fragment. When the denatured protein was diluted in a 20-fold refolding buffer containing $440 \mathrm{mM}$ L-arginine, a good solubility level of the refolded protein was attained. The addition of L-arginine increased the solubility by $53.6 \%(2.15$-fold $)$ compared with the absence of L-arginine (Figure $3 \mathrm{~B}$ ). The purity of refolded $\mathrm{scFv}$ was analyzed more than $55 \%$ in the soluble fraction by SDS-PAGE (Figure 3C). To increase stability of the refolded scFv, the refolding process was maintained at a low temperature $\left(4^{\circ} \mathrm{C}\right)$ because a significant amount of aggregation occurred during refolding at room temperature $\left(26^{\circ} \mathrm{C}\right)$. Finally, the refolded scFvs were separated from the aggregated proteins and the low molecule contaminants using size exclusion chromatography (SEC). The calculated size of the scFv by SEC was approximately 28-29 kDa, which according to SDS-PAGE, showed a single purified band of protein (Figure 4). The structural feature of $\mathrm{scFv}$ was verified through secondary structure analysis using circular dichroism (CD). From the CD spectra analysis, the secondary structure of scFv was estimated to consist of $44.8 \% \beta$-sheet, $0.9 \% \alpha$-helix, and $54.3 \%$ random structure, which is in good agreement with the secondary structure prediction based on the amino acid sequence (Figure 5).

Figure 3. Purification and refolding of the $s c F v$ antibody fragment. (A) Solubilized $s c F v$ was applied to a Ni-column and eluted by a gradient of $250 \mathrm{mM}$ imidazole (lane 1, before column; lane 2, unbound; lane 3, wash); (B) The scFv fragment was refolded in the presence of $440 \mathrm{mM} \mathrm{L}$-arginine and the redox reagents, $2 \mathrm{mM} \mathrm{GSH}$ and $0.2 \mathrm{mM} \mathrm{GSSH}$ (lanes 1 and 4 , before refolding sample; lanes 2 and 5, the supernatant after refolding; lanes 3 and 6, the pellet after refolding); and (C) The final refolded $\mathrm{scFv}$ antibody fragment.

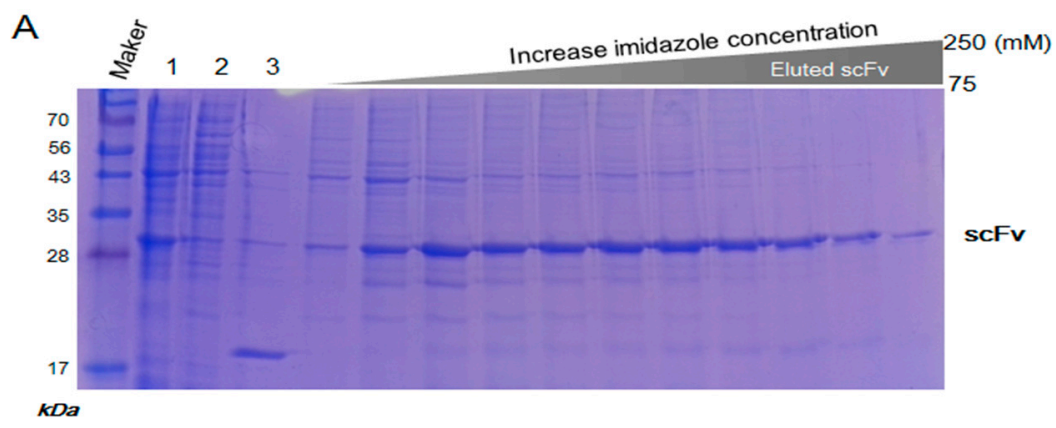


Figure 3. Cont.

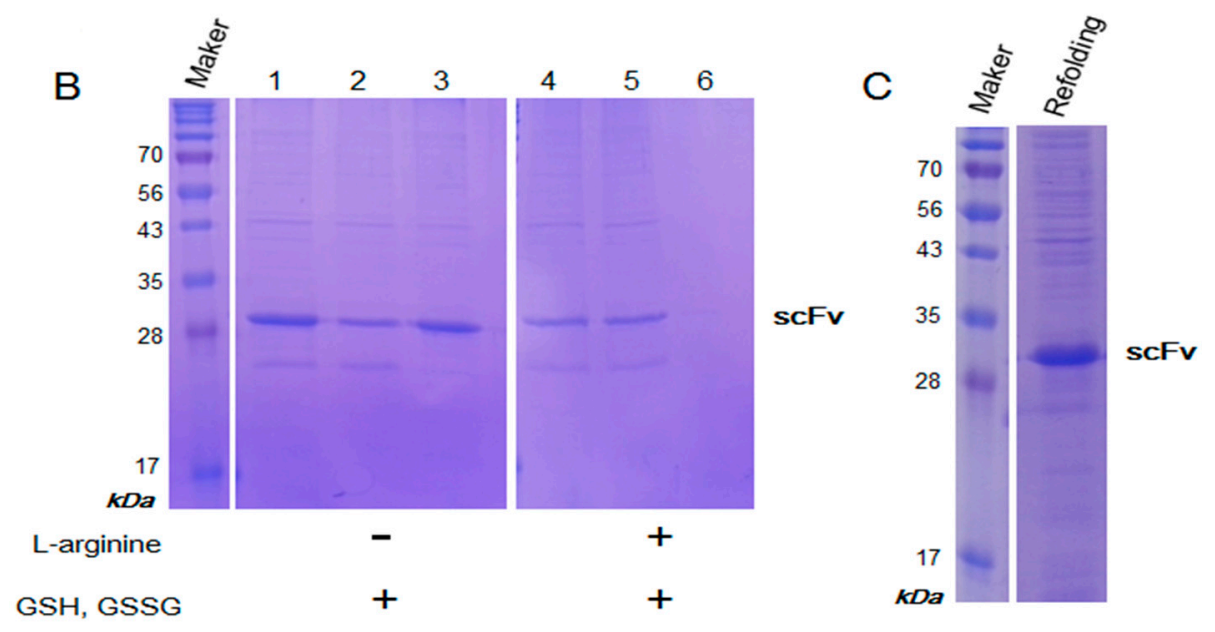

Figure 4. Molecular mass of scFv using a gel filtration column. Molecular weights for standard proteins are as follows: Conalbumin, $75 \mathrm{kDa}, 9.55 \mathrm{~mL}$; ovalbumin, $43 \mathrm{kDa}, 10.31 \mathrm{~mL}$; Carbonic anhydrase, $29 \mathrm{kDa}, 11.65 \mathrm{~mL}$; Aprotinin, $6.5 \mathrm{kDa}, 15.33 \mathrm{~mL}$; (gel filtration calibration kit LMW and HMW, GE Healthcare, Piscataway, NJ, USA) The scFv fragment, indicated by a black arrow, with the expected molecular weight of $29 \mathrm{kDa}$ was eluted at the elution volume of $12.04 \mathrm{~mL}$ close to the carbonic anhydrase. The gel-phase distribution coefficient $\left(K_{\mathrm{av}}\right)$ was calculated from: $K_{\mathrm{av}}=\left(V_{\mathrm{e}}-V_{\mathrm{o}}\right) /\left(V_{\mathrm{c}}-V_{\mathrm{o}}\right)$ where $V_{\mathrm{e}}$ is elution volume, $V_{\mathrm{o}}(7.61 \mathrm{~mL})$ is void volume (determined using blue dextran), and $V_{\mathrm{c}}(24 \mathrm{~mL})$ is column volume.

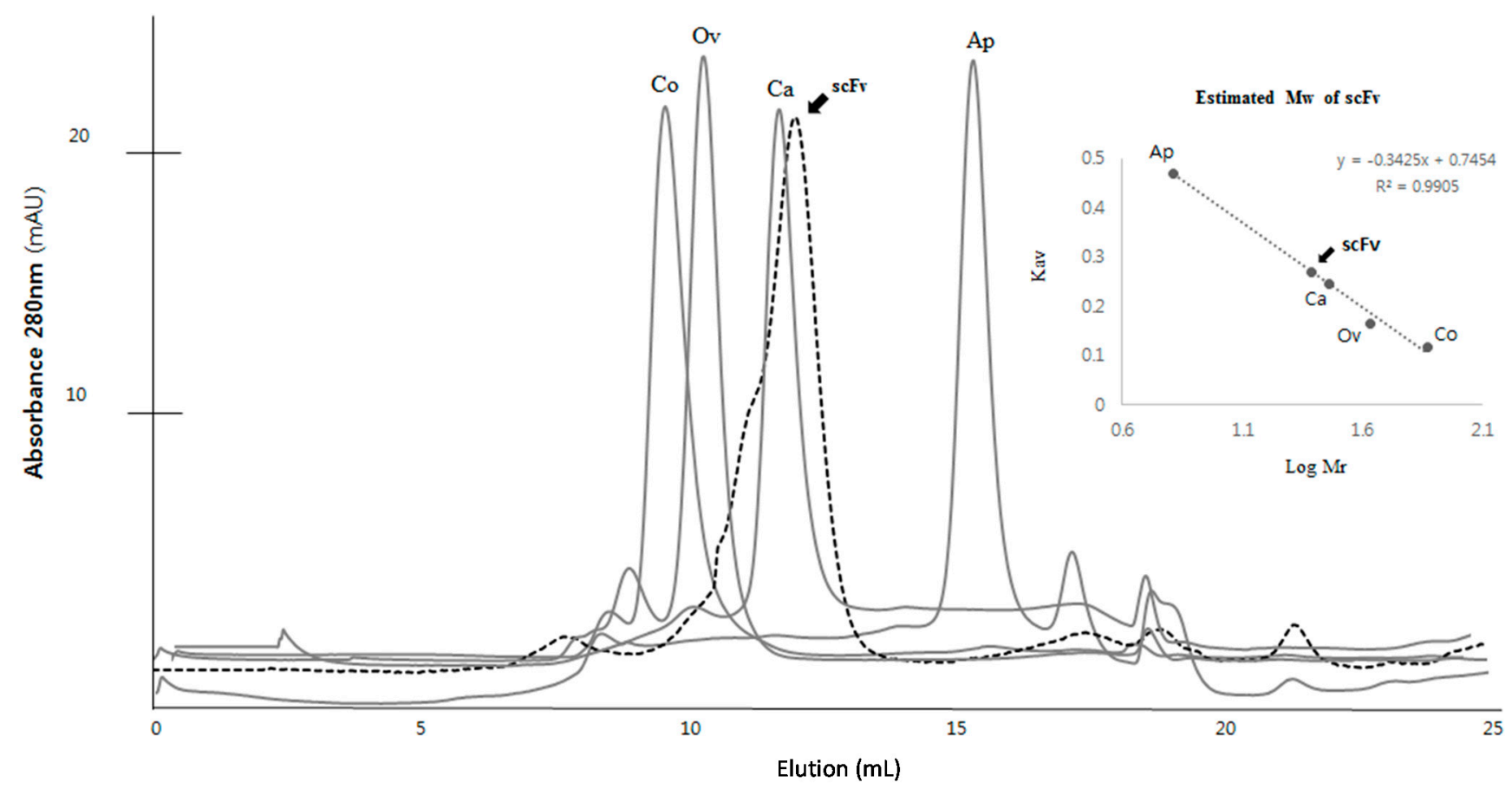


Figure 5. Far-UV circular dichroism (CD) spectra for the refolded $\mathrm{scFv}$. The $\mathrm{scFv}$ fragment $(0.5 \mu \mathrm{g} / \mathrm{mL})$ dissolved in $50 \mathrm{mM}$ Tris $\mathrm{pH} 7.5,100 \mathrm{mM} \mathrm{NaCl}$ and $5 \%$ glycerol was analyzed at room temperature.

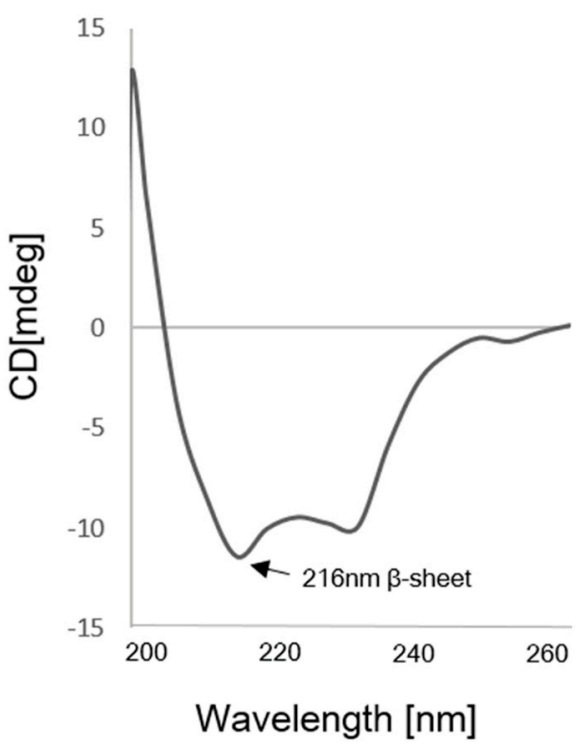

\subsection{Kinetics Assay with Myoglobin Antigen}

We tested whether the refolded $\mathrm{scFv}$ has a binding activity to human myoglobin antigen as compared to the whole parental antibody. The antibody binding was investigated using the enzyme-linked immunosorbent assay (ELISA). The refolded scFv showed a relatively weaker interaction with human myoglobin at a low concentration. However, it showed a comparable affinity value (optical density, (OD)) to the parent premature antibody at a higher concentration (Figure 6A). The refolded scFv showed binding affinity to both human myoglobin and equine myoglobin whereas it did not bind to other proteins, such as hemoglobin or conalbumin, being consistent with the binding pattern of the parental antibody. Despite the high sequence similarity between myoglobins, the purified scFv exhibited a significantly higher binding affinity to human myoglobin than to equine myoglobin, indicating its specificity toward human antigen (Figure 6B). Recently we identified the epitope site of the premature antibody to be the $C$-terminal region of the myoglobin antigen [28]. Consistently, the refolded scFv showed binding absorbance to the $C$-terminal region of the myoglobin peptide, aa 144-154, with negligible binding to other peptides (Figure 6C). To further test the binding affinity, a label-free sensor system was used to measure the association and dissociation kinetics against human myoglobin coated on the APS sensor tip surfaces. The result showed effective binding between the refolded $\mathrm{scFv}$ and the target antigen, whereas it did not bind the BSA of the negative control. The assay in the Octet system showed an increased intensity with an increase in the scFvs concentration with a repetitive binding pattern in the continuous binding analysis (Figure 6D,E). The measured values of the association rate constant $\left(k_{\mathrm{on}}\right)$ and the dissociation rate constant $\left(k_{\text {off }}\right)$ for the refolded $\mathrm{scFv}$ were $9.32 \times 10^{4} \mathrm{M}^{-1} \cdot \mathrm{s}^{-1}$ and $6.29 \times 10^{-3}$ $\mathrm{s}^{-1}$, respectively, with an overall affinity value $\left(K_{\mathrm{D}}=k_{\text {off }} / k_{\text {on }}\right)$ of $10^{-8} \mathrm{M}$ (Figure $\left.6 \mathrm{E}\right)$. Compared with the intact premature antibody, the kinetics data showed that the association rate decreased 38.6-fold from $3.6 \times 10^{6}$ to $9.32 \times 10^{4}$ with a dissociation value showing a 1.6-fold reduction, yielding an overall decrease in the affinity by 23.3-fold [1]. Despite the reduction of the association value, the refolded scFv 
showed a significantly high dissociation value, maintaining the same unique binding patterns of rapid kinetics of the parent antibody.

Figure 6. Binding analysis of the refolded scFv fragment. (A) Enzyme-linked immunosorbent assay (ELISA) analysis for the binding of scFv on the human myoglobin coated surface. Serial dilutions $(\times 1 / 10)$ were made for the premature antibody and the refolded fragment with an initial concentration of 0.1 and $30 \mu \mathrm{g} / \mathrm{mL}$, respectively; (B) Comparative ELISA analysis of the refolded $\mathrm{scFv}$ and the whole antibody for human myoglobin, equine myoglobin, conalbumin and hemoglobin ( $\mathrm{scFv} 1.9 \mu \mathrm{g} / \mathrm{mL}$, IgG2-7Ds $0.5 \mu \mathrm{g} / \mathrm{mL}$ ); (C) Comparative ELISA analysis of the refolded $\mathrm{scFv}$ and the whole antibody for synthetic peptides of human myoglobin and human cardiac troponin I (scFv $1.9 \mu \mathrm{g} / \mathrm{mL}, \mathrm{IgG} 2-7 \mathrm{Ds}$ $0.5 \mu \mathrm{g} / \mathrm{mL}$ ); (D) The binding pattern was analyzed by an Octet-RED immunosensor; (E) The binding pattern was analyzed using increment of $\mathrm{scFv}$ in a continuous manner; and (F) The comparison of the kinetic parameter values for the parent premature antibody and the refolded scFv was performed using the Data Analysis 7.0 program.

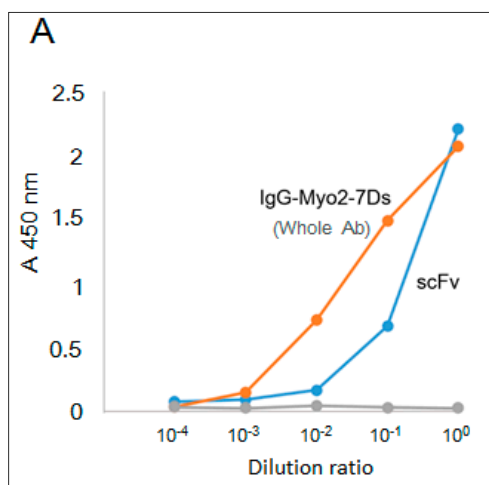

$\mathrm{D}$

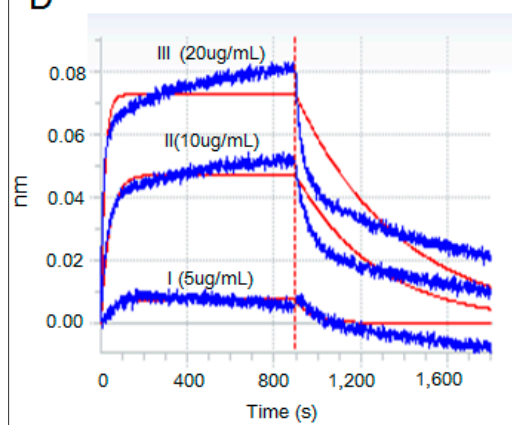

\section{B}

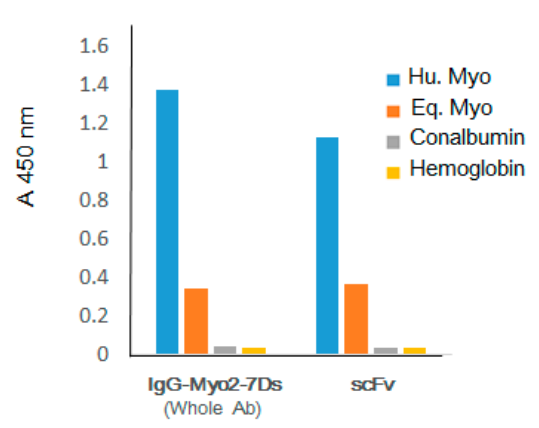

E

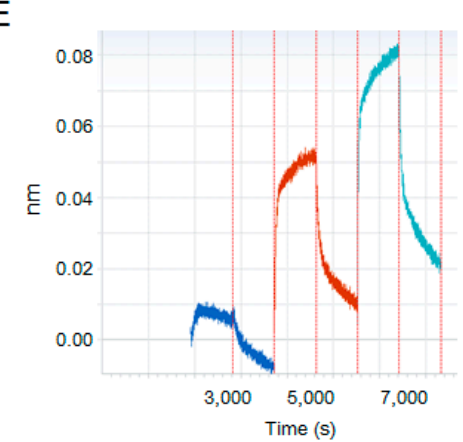

C

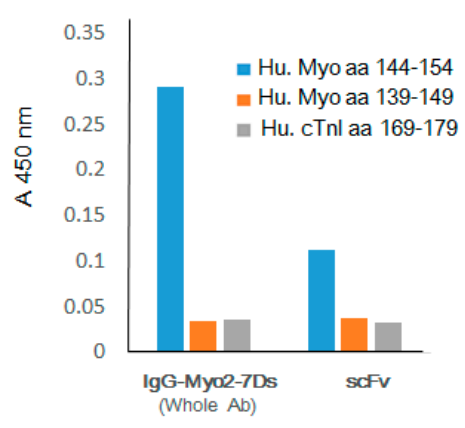

$\mathrm{F}$

\begin{tabular}{r|c|c|c|} 
& $\mathrm{K}_{\text {on }}(1 / \mathrm{Ms})$ & $\mathrm{K}_{\text {off }}(1 / \mathrm{s})$ & $\mathrm{K}_{\mathrm{D}}(\mathrm{M})$ \\
\hline $\begin{array}{r}\mathrm{scFv} \\
\text { IgG-Myo2-7Ds } \\
\text { Whole antibody) }\end{array}$ & $9.32 \times 10^{4}$ & $6.29 \times 10^{-3}$ & $6.11 \times 10^{-8}$ \\
\hline $\begin{array}{r}\text { Kinetic value } \\
\text { change } \\
\text { (folds) }\end{array}$ & 38.6 & 1.6 & 21.1 \\
\hline
\end{tabular}

\section{Discussion}

In this study, we successfully refolded premature antibody from $E$. coli inclusion bodies using the refolding buffer containing L-arginine. The L-arginine molecule has been known to be a component that minimizes self-aggregation of denatured proteins by increasing their solubility during the refolding process [29-31]. In our study, the scFvs in the refolding buffer without L-arginine aggregated noticeably, whereas addition of L-arginine showed a significant increase in the refolding yield. Protein homology modeling based on previous antibody structures suggests that $29.4 \%$ of hydrophobic residues, such as I, $\mathrm{V}, \mathrm{W}, \mathrm{Y}, \mathrm{F}$, in the CDR region are exposed on the surface. These structural and sequential elements may 
have caused the aggregation during purification at a high concentration, even in the presence of $10 \%$ glycerol. This result clearly showed that L-arginine stabilized the exposed hydrophobic areas of the recombinant protein and suppressed aggregation of a partially folded intermediate during the refolding procedure. For correct refolding, the redox components GSH and GSSG were supplied in addition to Larginine in this study. In general, when the native target protein contains disulfides, the redox reagents provide a favorable condition for folding because the rates and yields of the refolding reactions are highly dependent on the redox condition [32], whereas the optimal redox conditions differ for each protein and each set of buffer conditions. Redox reagents reduce non-native protein-protein disulfides that hold the protein in an incompletely oxidized form. In addition, an oxidant, such as GSSG, is essential for disulfide bond formation, although excess GSSG can cause free sulfhydryls of the protein to form disulfides with glutathione that consequently inhibit intramolecular disulfide linkage formation [33].

Using refolded protein partitioned in the inclusion body, we produced an active scFv fragment that could be useful in research and clinical settings due to the modifiable pharmacokinetic properties compared with the parent whole antibodies. Due to their relatively small molecular weight, scFv proteins can be effective in tissue penetration with the relative ease of mass-producing them at a low cost. Here, we successfully refolded the recombinant $\mathrm{scFv}$ protein, retaining the original rapid kinetics of the parent premature antibody. The resultant $\mathrm{scFv}$ showed a relatively weak association rate with the myoglobin antigen compared with the parental whole antibody. We assume that this result is partly due to the monovalent binding property of $\mathrm{scFv}[34,35]$ and partly due to the altered detection method in which the additional wash step was used for detection of the histidine tag at the $N$-terminus of the recombinant antibody. Given the monovalent binding property of scFv and the altered secondary antibody for ELISA detection, the recombinant $\mathrm{scFv}$ protein appears to retain a comparable level of rapid kinetics with the parent antibody. Although they have a lower binding affinity, these fragments can be genetically modified to enhance desirable properties in multivalency and high target retention. For example, the $\mathrm{scFv}$ can be used in dimers, diabodies, IgG, or multivalent molecules to increase the avidity of low affinity monomers to target antigens. The mechanism of the rapid binding kinetics of the premature antibody remains unknown. An additional biochemical study using the refolded scFv retaining the same binding characteristics of the parent antibody would assist in the comprehension of the molecular mechanism of the unique binding pattern of the premature antibody and the development of an engineered antibody that can be used in a continuous detection system for AMI patients.

\section{Experimental Section}

\subsection{Plasmid Construction for the Expression of Recombinant $s c F v$}

Hybridoma Myo2-7Ds cells were prepared as previously described [1]. The total RNA isolated from hybridoma cells using the TRIzol reagent (Invitrogen, Carlsbad, CA, USA) was used as the template for the synthesis of complementary DNA (cDNA) [36]. A GeneRacer kit (Invitrogen) was used for the cDNA preparation according to the procedures recommended by the manufacturer. The gene fragments for the variable regions of $V_{\mathrm{H}}$ and $V_{\mathrm{L}}$ were amplified using the cDNA as the template, and the assembled full gene fragment for scFv-Myo2-7Ds with a (GGGGS) $\times 3$ linker was constructed. The scFv sequence was amplified using primers scFv-Myo-NheI Fw: 5'-GCGCGCTAGCGATGTTTTGATGACCCAA-3' and 
scFv-Myo-XhoI Rev: 5'-AAGCTGGAAATAAAATAGCTCGAGGCGC-3' by polymerase chain reaction. The $s c F v$ gene fragment was cloned in $\mathrm{pET}-28 \mathrm{a}(+)$ into the NheI/XhoI restriction sites, and the resulting plasmid was designated as pET28a-scFv-Myo2-7Ds6 $\times$ H. The thrombin cleavage site of pET28a $(+)$ was replaced with the TEV cleavage site, and the vector system was composed of a $6 \times$ His tag at the $N$-terminus with kanamycin tolerance for bacterial growth.

\subsection{Expression and Isolation of scFv from Inclusion Bodies}

The scFv expression vector was transformed using E. coli BL21/DE3/RIL competent cells, which were incubated with shaking at $37{ }^{\circ} \mathrm{C}$ in Luria Broth (LB) medium supplemented with $30 \mu \mathrm{g} / \mathrm{mL}$ kanamycin. When the OD (optical density) of the cell growth reached 0.6 , the induction of $\mathrm{scFv}$ expression by the addition of $1 \mathrm{mM}$ IPTG was performed over $4 \mathrm{~h} 30 \mathrm{~min}$ at $30{ }^{\circ} \mathrm{C}$ at $10 \times \mathrm{g}$. The cells were then collected by centrifugation for $30 \mathrm{~min}$ at $4615 \times \mathrm{g}$ and stored at $-20{ }^{\circ} \mathrm{C}$. The cell pellet $(4 \mathrm{~g})$ was thawed at room temperature and subjected to sonication $(1 \mathrm{~s} \mathrm{on} / \mathrm{off}, 60 \%$ amplitude for $2 \mathrm{~min}$; repeated 3 times) in lysis buffer $100 \mathrm{~mL}$ containing phosphate-buffered saline (PBS: $137 \mathrm{mM} \mathrm{NaCl}$, $27 \mathrm{mM} \mathrm{KCl}, 100 \mathrm{mM} \mathrm{Na} 2 \mathrm{HPO}_{4}, 20 \mathrm{mM} \mathrm{KH}_{2} \mathrm{PO}_{4}, \mathrm{pH}$ approximately 7.4), $1 \mathrm{mM}$ PMSF and a protein inhibitor cocktail tablet. The cell lysate was incubated for $30 \mathrm{~min}$ on ice and then centrifuged at $15,000 \times \mathrm{g}$ for $15 \mathrm{~min}$ at $4{ }^{\circ} \mathrm{C}$ to pellet the insoluble material (inclusion bodies). The pellet was suspended in a $100 \mathrm{~mL}$ buffer of $50 \mathrm{mM}$ Tris, $10 \mathrm{mM}$ EDTA, $5 \mathrm{mM}$ DTT, 2\% Triton X-100, and $500 \mathrm{mM} \mathrm{NaCl}$ adjusted to $\mathrm{pH} 7.5$, and the solution was vortexed to ensure that the pellet was completely suspended. The suspension was centrifuged at $15,000 \times \mathrm{g}$ for $15 \mathrm{~min}$ at $4{ }^{\circ} \mathrm{C}$ to pellet the inclusion bodies (the isolation wash step, repeated twice). The pellet was resuspended in $100 \mathrm{~mL}$ buffer of $50 \mathrm{mM}$ Tris and $10 \mathrm{mM}$ EDTA adjusted to $\mathrm{pH} 7.5$, and the suspension was transferred to a centrifuge tube of known weight and centrifuged at $15,000 \times \mathrm{g}$ for $15 \mathrm{~min}$ at $4{ }^{\circ} \mathrm{C}$ to pellet the inclusion bodies.

\subsection{Purification and Refolding of $s c F v$}

The purified inclusion bodies pellet $(2.5 \mathrm{~g}$ ) was solubilized in $120 \mathrm{~mL}$ of $50 \mathrm{mM}$ Tris, $\mathrm{pH} 7.5 \mathrm{buffer}$ with $8 \mathrm{M}$ urea at $4{ }^{\circ} \mathrm{C}$ overnight. After centrifugation at $15,000 \times \mathrm{g}$ for $50 \mathrm{~min}$, the supernatant containing the solubilized $\mathrm{scFv}$ was purified using a 25 to $500 \mathrm{mM}$ linear imidazole gradient in $50 \mathrm{mM}$ Tris, 300 $\mathrm{mM} \mathrm{NaCl}, 6 \mathrm{M}$ urea and $1 \mathrm{mM}$ PMSF, $\mathrm{pH} 7.5$ on a Histrap HP $5 \mathrm{~mL}$ column using the AKTA purifier (GE Healthcare). The denatured $\mathrm{scFv}$ in $6 \mathrm{M}$ urea was refolded using the previously described technique [37,38]. The purified scFv solution was rapidly diluted in 19 volumes of refolding buffer (55 mM Tris, $21 \mathrm{mM} \mathrm{NaCl}, 0.88 \mathrm{mM} \mathrm{KCl}, 1 \mathrm{mM}$ EDTA, $2 \mathrm{mM} \mathrm{GSH}$ and $0.2 \mathrm{mM} \mathrm{GSSG}, \mathrm{pH} 8.2$ ) at $4{ }^{\circ} \mathrm{C}$ for $24 \mathrm{~h}$. The soluble scFv was collected by centrifugation at $15,000 \times g$ for $30 \mathrm{~min}$ at $4{ }^{\circ} \mathrm{C}$ to remove the aggregated scFv, dialyzed in TBS (50 mM Tris and $100 \mathrm{mM} \mathrm{NaCl}, \mathrm{pH} 7.5)$, and then concentrated using a Centricon microconcentrator (Vivaspin 10K MWCO, Sartorius, Weender Landstr, Germany). The concentrate was applied to a Superdex 75 10/300 GL column (prep grade, GE Healthcare) equilibrated with $50 \mathrm{mM}$ Tris, $100 \mathrm{mM} \mathrm{NaCl}$, and 5\% glycerol, $\mathrm{pH} 7.5$ and eluted in the downward flow mode at a flow rate of $0.4 \mathrm{~mL} / \mathrm{min}$. The fractions were assayed for $\mathrm{A}_{280}$ and analyzed for protein contents by SDS-PAGE. The scFv peak fractions were pooled and stored at $2-8{ }^{\circ} \mathrm{C}$. Standard marker proteins (Gel filtration calibration kit LMW, GE Healthcare) were used for molecular weight of the protein in solution. 


\subsection{Circular Dichroism Analysis of $s c F v$}

CD spectroscopy was performed on a Jasco J-815 spectropolarimeter (Jasco, Tokyo, Japan). The spectra were recorded using a 1-mm path length cell (equilibrated at room temperature) in a wavelength range from 190 to $260 \mathrm{~nm}$ with $1-\mathrm{nm}$ resolution at $50 \mathrm{~nm} / \mathrm{min}$ scanning speed and a $1 \mathrm{~s}$ response time. A concentration of $0.5 \mathrm{mg} / \mathrm{mL} \mathrm{scFv}$ was dissolved in $50 \mathrm{mM}$ Tris, $100 \mathrm{mM} \mathrm{NaCl}$, and $5 \%$ glycerol.

\subsection{Enzyme-Linked Immunosorbent Assay}

The binding activity of refolded scFv was determined by ELISA. $100 \mu \mathrm{L}$ of the antigen (human myoglobin; $5 \mu \mathrm{g} / \mathrm{mL}$ ) dissolved in carbonate buffer ( $15 \mathrm{mM} \mathrm{Na} \mathrm{CO}_{3}, 35 \mathrm{mM} \mathrm{NaHCO}$, $0.2 \mathrm{~g} / \mathrm{L} \mathrm{NaN}_{3}$; pH 9.6) was coated onto each well of a 96-well microarray plate (SPL Life Sciences, Seoul, Korea) at $4{ }^{\circ} \mathrm{C}$ for $16 \mathrm{~h}$. After washing with PBS-T (0.05\% Tween-20 in PBS) three times, the coated antigens were blocked with $200 \mu \mathrm{L} /$ well of blocking buffer $(10 \mathrm{mg} / \mathrm{mL}$ bovine serum albumin in PBST) for $1 \mathrm{~h}$ at $37^{\circ} \mathrm{C}$. Serially diluted refolded protein and premature antibody were added to the coated each wells and allowed to bind for $1 \mathrm{~h}$ at $37^{\circ} \mathrm{C}$. After washing, $100 \mu \mathrm{L}$ of 1:2500 diluted anti-6× His tag antibody (Abcam, Cambridge, MA, USA) dissolved in antibody dilution buffer (3\% BSA in PBST) was added to each well and allowed to react for $1 \mathrm{~h}$. After washing, $100 \mu \mathrm{L}$ of 1:5000 diluted goat-anti-Mouse in secondary-HRP conjugated antibody dissolved in antibody dilution buffer was added to each well and allowed to react for $1 \mathrm{~h}$. After washing, $100 \mu \mathrm{L}$ of a TMB peroxidase substrate system (BD, Franklin Lakes, NJ, USA) was added to each well for detection and $50 \mu \mathrm{L}$ of $1 \mathrm{~N} \mathrm{H}_{2} \mathrm{SO}_{4}$ was added as stopping reagent. The signals were quantified by measuring absorbance at $450 \mathrm{~nm}$ by using a spectrophotometer (Bio-Rad, Hercules, CA, USA). For comparison, BSA was coated onto the plate, and all the steps as previously described were performed.

\subsection{Reaction Kinetics of Myoglobin Binding to $s c F v$}

The association and dissociation kinetics of myoglobin and $\mathrm{scFv}$ were analyzed using the label-free sensor system, Octet Red (ForteBio, Menlo Park, CA, USA), according to the manufacturer's protocol. Human myoglobin $(5 \mu \mathrm{g} / \mathrm{mL})$ in phosphate-buffered saline (PBS, pH 7.4) was immobilized on the surfaces of an APS disposable sensor tip at $30{ }^{\circ} \mathrm{C}$ for $900 \mathrm{~s}$, and the residual surfaces were blocked by $0.5 \%$ casein in PBS (casein-PBS). The myoglobin-immobilized sensor was dipped into the antibody solution $(1 \mu \mathrm{g} / \mathrm{mL})$ in casein-PBS to analyze the association reaction and was subsequently returned to the casein-PBS solution to analyze the dissociation reaction. The association and dissociation kinetic curves were obtained by subtracting the data obtained in the absence of myoglobin using the Data Analysis 7 program (ForteBio). The rate constants for association $\left(k_{\mathrm{on}}\right)$ and dissociation $\left(k_{\mathrm{off}}\right)$ were obtained by regression analysis using the Data Analysis 7 program, and the equilibrium association constant $\left(K_{\mathrm{A}}\right)$ was calculated using the equation $K_{\mathrm{A}}=k_{\mathrm{on}} / k_{\mathrm{off}}$.

\section{Conclusions}

Research on premature antibodies is still in its infancy and the detailed binding mechanism of the rapid reaction is not known yet. Here, we produced the $s c F v$ of the premature antibody for human myoglobin antigen, purified it from inclusion body and successfully refolded to active form using 
reagents including arginine and DTT. The refolded $\mathrm{scFv}$ retains the unique rapid reaction binding activity toward myoglobin. The active scFv fragment could be used for research in understanding the binding mechanism of the rapid dissociation and the development of an engineered antibody in continuous system for AMI patients.

\section{Acknowledgments}

This research was supported in part by the Converging Research Center Program through the National Research Foundation of Korea (NRF) funded by the Ministry of Science, ICT and Future Planning (No. 2013K000249/ NRF-2011-0017040) and partially by a grant from the KRIBB Research Initiative Program.

\section{Author Contributions}

Eui-Jeon Woo and Se-Hwan Paek contributed to the study concept, manuscript drafting and editing. Hyung-Nam Song performed the experiments and analyzed the data. Myung Kyu Lee designed the kinetic model. Jun-Hyuck Jang, Young-Wan Kim provided DNA construction. Sung-Goo Park and Dong-Hyung Kim gave technical support and conceptual advice.

\section{Conflicts of Interest}

The authors declare no conflict of interest.

\section{References}

1. Kim, D.H.; Seo, S.M.; Paek, S.H.; Lim, G.S. Premature antibodies with rapid reaction kinetics and their characterization for diagnostic applications. Anal. Biochem. 2012, 420, 54-60.

2. Cho, H.K.; Seo, S.M.; Cho, I.H.; Paek, S.H.; Kim, D.H. Minimum-step immuno-analysis based on continuous recycling of the capture antibody. Analyst 2011, 136, 1374-1379.

3. Paek, S.H.; Cho, I.H.; Seo, S.M.; Kim, D.H. Production of rapidly reversible antibody and its performance characterization as binder for continuous glucose monitoring. Analyst 2011, 136, 4268-4276.

4. Kim, D.H.; Paek, S.H.; Lim, G.S.; Jeon, J.W. Performance characteristics of monoclonal antibodies as recyclable binders to cardiac troponin I. Anal. Biochem. 2012, 431, 11-18.

5. Sagawa, T.; Oda, M.; Ishimura, M.; Furukawa, K.; Azuma, T. Thermodynamic and kinetic aspects of antibody evolution during the immune response to hapten. Mol. Immunol. 2003, 39, 801-808.

6. Boes, M. Role of natural and immune igm antibodies in immune responses. Mol. Immunol. 2000, 37, 1141-1149.

7. Strandh, M.; Andersson, H.S.; Ohlson, S. Weak affinity chromatography. Methods Mol. Biol. 2000, 147, 7-23.

8. Ohlson, S.; Jungar, C.; Strandh, M.; Mandenius, C.F. Continuous weak-affinity immunosensing. Trends Biotechnol. 2000, 18, 49-52.

9. Jungar, C.; Strandh, M.; Ohlson, S.; Mandenius, C.F. Analysis of carbohydrates using liquid chromatography_Surface plasmon resonance immunosensing systems. Anal. Biochem. 2000, 281, $151-158$. 
10. Paek, S.H.; Cho, I.H.; Kim, D.H.; Jeon, J.W.; Lim, G.S. Label-free, needle-type biosensor for continuous glucose monitoring based on competitive binding. Biosens. Bioelectron. 2013, 40, 38-44.

11. Kagen, L.; Scheidt, S.; Roberts, L.; Porter, A.; Paul, H. Myoglobinemia following acute myocardial infarction. Am. J. Med. 1975, 58, 177-182.

12. Chiu, A.; Chan, W.K.; Cheng, S.H.; Leung, C.K.; Choi, C.H. Troponin-I, myoglobin, and mass concentration of creatine kinase-MB in acute myocardial infarction. QJM 1999, 92, 711-718.

13. Gnedenko, O.V.; Mezentsev, Y.V.; Molnar, A.A.; Lisitsa, A.V.; Ivanov, A.S.; Archakov, A.I. Highly sensitive detection of human cardiac myoglobin using a reverse sandwich immunoassay with a gold nanoparticle-enhanced surface plasmon resonance biosensor. Anal. Chim. Acta 2013, $759,105-109$.

14. Timucin, C.; Gul, O.; Kutuk, O.; Basaga, H. Antibody array-based immunosensor for detecting cardiovascular disease risk markers. J. Immunoass. Immunochem. 2012, 33, 275-290.

15. Henares, T.G.; Mizutani, F.; Hisamoto, H. Current development in microfluidic immunosensing chip. Anal. Chim. Acta 2008, 611, 17-30.

16. Lee, Y.H.; Iijima, M.; Kado, Y.; Mizohata, E.; Inoue, T.; Sugiyama, A.; Doi, H.; Shibasaki, Y.; Kodama, T. Construction and characterization of functional anti-epiregulin humanized monoclonal antibodies. Biochem. Biophys. Res. Commun. 2013, 441, 1011-1017.

17. Dobhal, S.; Chaudhary, V.K.; Singh, A.; Pandey, D.; Kumar, A.; Agrawal, S. Expression of recombinant antibody (single chain antibody fragment) in transgenic plant Nicotiana tabacum cv. Xanthi. Mol. Biol. Rep. 2013, 40, 7027-7037.

18. Kobayashi, N.; Odaka, K.; Uehara, T.; Imanaka-Yoshida, K.; Kato, Y.; Oyama, H.; Tadokoro, H.; Akizawa, H.; Tanada, S.; Hiroe, M.; et al. Toward in vivo imaging of heart disease using a radiolabeled single-chain Fv fragment targeting Tenascin-C. Anal. Chem. 2011, 83, 9123-9130.

19. Gilmartin, A.A.; Lamp, B.; Rumenapf, T.; Persson, M.A.; Rey, F.A.; Krey, T. High-level secretion of recombinant monomeric murine and human single-chain Fv antibodies from drosophila S2 cells. Protein Eng. Des. Sel. 2012, 25, 59-66.

20. Vaks, L.; Benhar, I. Production of stabilized $\mathrm{scFv}$ antibody fragments in the E. coli bacterial cytoplasm. Methods Mol. Biol. 2014, 1060, 171-184.

21. Onishi, H.; Mizukami, M.; Hanagata, H.; Tokunaga, M.; Arakawa, T.; Miyauchi, A. Efficient production of anti-fluorescein and anti-lysozyme as single-chain anti-body fragments (scFv) by Brevibacillus expression system. Protein Expr. Purif. 2013, 91, 184-191.

22. Huston, J.S.; Levinson, D.; Mudgett-Hunter, M.; Tai, M.S.; Novotny, J.; Margolies, M.N.; Ridge, R.J.; Bruccoleri, R.E.; Haber, E.; Crea, R.; et al. Protein engineering of antibody binding sites: Recovery of specific activity in an anti-digoxin single-chain Fv analogue produced in escherichia coli. Proc. Natl. Acad. Sci. USA 1988, 85, 5879-5883.

23. Worn, A.; Pluckthun, A. Stability engineering of antibody single-chain Fv fragments. J. Mol. Biol. 2001, 305, 989-1010.

24. Joosten, V.; Lokman, C.; van den Hondel, C.A.; Punt, P.J. The production of antibody fragments and antibody fusion proteins by yeasts and filamentous fungi. Microb. Cell Fact. 2003, 2, 1.

25. Pluckthun, A. Escherichia coli producing recombinant antibodies. Bioprocess Technol. 1994, 19, 233-252. 
26. Gu, Z.; Weidenhaupt, M.; Ivanova, N.; Pavlov, M.; Xu, B.; Su, Z.G.; Janson, J.C. Chromatographic methods for the isolation of, and refolding of proteins from, escherichia coli inclusion bodies. Protein Expr. Purif. 2002, 25, 174-179.

27. Huang, Q.; Chen, L.; Zeng, L.; Wan, L.; Li, S.; Lu, X.; Cheng, J. Evaluation of three in vitro refolding methods for human-derived anti-CTLA4 scFv expressed in E. coli. Sheng Wu Yi Xue Gong Cheng Xue Za Zhi 2006, 23, 388-391. (In Chinese)

28. Song, H.N.; Kim, D.H.; Paek, S.H.; Park, S.G.; Lee, M.K.; Woo, E.J. Purification and characterization of Fab fragments with rapid reaction kinetics against myoglobin. Biosci. Biotech. Biochem. 2014, in press.

29. Umetsu, M.; Tsumoto, K.; Hara, M.; Ashish, K.; Goda, S.; Adschiri, T.; Kumagai, I. How additives influence the refolding of immunoglobulin-folded proteins in a stepwise dialysis system. Spectroscopic evidence for highly efficient refolding of a single-chain Fv fragment. J. Biol. Chem. 2003, 278, 8979-8987.

30. Choi, S.P.; Park, Y.C.; Lee, J.; Sim, S.J.; Chang, H.N. Effects of L-arginine on refolding of lysine-tagged human insulin-like growth factor 1 expressed in Escherichia coli. Bioprocess Biosyst. Eng. 2012, 35, 255-263.

31. Tischer, A.; Lilie, H.; Rudolph, R.; Lange, C. L-Arginine hydrochloride increases the solubility of folded and unfolded recombinant plasminogen activator rPA. Protein Sci. 2010, 19, 1783-1795.

32. Lu, D.; Liu, Z. Dynamic redox environment-intensified disulfide bond shuffling for protein refolding in vitro: Molecular simulation and experimental validation. J. Phys. Chem. B 2008, 112, 15127-15133.

33. St John, R.J.; Carpenter, J.F.; Randolph, T.W. High-pressure refolding of disulfide-cross-linked lysozyme aggregates: Thermodynamics and optimization. Biotechnol. Prog. 2002, 18, 565-571.

34. Liu, J.L.; Zabetakis, D.; Acevedo-Velez, G.; Goldman, E.R.; Anderson, G.P. Comparison of an antibody and its recombinant derivative for the detection of the small molecule explosive 2,4,6-trinitrotoluene. Anal. Chim. Acta 2013, 759, 100-104.

35. Muramatsu, H.; Yoshikawa, K.; Hayashi, T.; Takasu, S.; Kawada, Y.; Uchida, K.; Sato, S.; Takahashi, T.; Saga, S.; Ueda, R. Production and characterization of an active single-chain variable fragment antibody recognizing CD25. Cancer Lett. 2005, 225, 225-236.

36. Rio, D.C.; Ares, M., Jr.; Hannon, G.J.; Nilsen, T.W. Purification of rna using trizol (tri reagent). Cold Spring Harb. Protoc. 2010, 2010, pdb-prot5439.

37. Lilie, H.; Schwarz, E.; Rudolph, R. Advances in refolding of proteins produced in E. coli. Curr. Opin. Biotechnol. 1998, 9, 497-501.

38. Wetlaufer, D.B.; Branca, P.A.; Chen, G.X. The oxidative folding of proteins by disulfide plus thiol does not correlate with redox potential. Protein Eng. 1987, 1, 141-146.

(C) 2014 by the authors; licensee MDPI, Basel, Switzerland. This article is an open access article distributed under the terms and conditions of the Creative Commons Attribution license (http://creativecommons.org/licenses/by/4.0/). 